\title{
Conserved water-mediated H-bonding dynamics of catalytic Asn 175 in plant thiol protease
}

\author{
Tapas K Nandi ${ }^{l}$, Hridoy R Bairagya ${ }^{l}$, Bishnu P Mukhopadhyay ${ }^{l, *}$, K SekaR ${ }^{2}$, Dipankar Sukul ${ }^{l}$ \\ and Asim K BerA ${ }^{3}$ \\ ${ }^{1}$ Department of Chemistry, National Institute of Technology, Durgapur 713 209, India \\ ${ }^{2}$ Bioinformatics Centre, Indian Institute of Science, Bangalore 560 012, India \\ ${ }^{3}$ Center for Advanced Research in Biotechnology, Rockville, Maryland 20850, USA
}

*Corresponding author (Email, bpmk2@yahoo.com)

The role of invariant water molecules in the activity of plant cysteine protease is ubiquitous in nature. On analysing the 11 different Protein DataBank (PDB) structures of plant thiol proteases, the two invariant water molecules W1 and W2 (W220 and W222 in the template 1PPN structure) were observed to form H-bonds with the $\mathrm{O}_{\mathrm{b}}$ atom of Asn 175. Extensive energy minimization and molecular dynamics simulation studies up to $2 \mathrm{~ns}$ on all the PDB and solvated structures clearly revealed the involvement of the H-bonding association of the two water molecules in fixing the orientation of the asparagine residue of the catalytic triad. From this study, it is suggested that H-bonding of the water molecule at the W1 invariant site better stabilizes the Asn residue at the active site of the catalytic triad.

[Nandi T K, Bairagya H R, Mukhopadhyay B P, Sekar K, Sukul D and Bera A K 2009 Conserved water-mediated H-bonding dynamics of catalytic Asn 175 in plant thiol protease; J. Biosci. 34 27-34]

\section{Introduction}

Cysteine proteases are responsible for intracellular proteolysis of various types and an abnormal increase in their activity results in the degradation of muscle proteins (Komatsu et al 1986). Their activity is mainly controlled by the three residues, Cys 25, His 159 and Asn 175 of the catalytic triad (Polgár 1974). The papain molecule is folded to form two interacting domains, each comprising residues from both the $\mathrm{N}$ - and $\mathrm{C}$-terminal sections of the polypeptide, which are separated by a cleft containing the active site. His 159 , located at the $\beta$-sheet of the right domain, can polarize and interact with the $\mathrm{SH}$ group of Cys 25 at the N-terminus of the L1 $\alpha$-helix of the left domain, forming a thiolateimidazolium ion-pair which influences the substrate- or inhibitor-binding propensity of the protein (Polgár 1974). Asn 175 is found to stabilize the thiolate-imidazolium ion-pair (Vernet et al 1995) through the formation of an $\mathrm{H}$ - bond between its side chain amide oxygen atom and $\mathrm{N}^{\mathrm{E} 2} \mathrm{H}$ atom of the catalytic His 159. Since this bond is observed to be collinear to the covalent $\mathrm{C}_{\beta}-\mathrm{C} \gamma$ bond of His 159 , the imidazole ring rotates about this bond without disrupting the hydrogen bond (Vernet et al 1995). Thus, the imidazole ring stays in an optimum position during the catalytic process.

In this study, we investigated the role of conserved water molecules around Asn 175 and their involvement in hydrogen-bonding interactions. It is proposed that the hydrogen bonds formed by oxygen atoms in water could influence the interaction of this Asn towards the catalytic triad. However, among the 13 conserved water molecules from the 11 different $\mathrm{X}$-ray structures (with resolutions higher than $2.20 \AA$ ) of plant thiol proteases (table 1), only two are observed to form $\mathrm{H}$-bonds with Asn 175 through the peptide backbone oxygen $\left(\mathrm{O}_{\mathrm{b}}\right)$ atom. The average distances between these two conserved water molecules fall between 5.4 and $5.8 \AA$ and they subtend an angle of $\sim 120^{\circ}-130^{\circ}$

Keywords. Conserved water in molecular recognition; MD simulation; plant cysteine protease

Abbreviations used: CHASA, conditional hydrophobic accessible surface area; IMD, interactive molecular dynamics; PDB, Protein DataBank; RMSD, root mean square deviation 
with the $\mathrm{O}_{b}$ of Asn 175. The role of one of these two water molecules (W222, which occupies the hydrophilic site of $1 \mathrm{PPN}$ ) has recently been described (O'Farrell and Joshua-Tor 2007). However, the other conserved water molecule (W220 in 1PPN) occupies a position that seems to hold the Cys 25 and Gln 19 residues (which are involved in the oxyanion intermediate) in the proper position through the $\mathrm{H}$-bond with both the $\mathrm{O}_{\mathrm{b}}$ atom of Asn 175 and $\mathrm{N}_{\mathrm{b}}$ atom of Lys 17. Thus, determining the role of Asn 175 in the catalytic process, that is, ion-pair stabilization, is thought to be important.

\section{Materials and methods}

All the X-ray structures of plant thiol proteases were taken from the Protein Data Bank (PDB) (Berman et al 2000) and their important parameters are included in table 1. Only one molecule was observed to be present in all the crystals - 1PPN (Pickersgill et al 1992), 9PAP (Kamphuis et al 1984), 1PE6 (Yamamoto et al 1991), 1PPP (Kim et al 1992), 1KHP (Janowski et al 2004), 1KHQ (Janowski et al 2004), 1BP4 (LaLonde et al 1998), 1AEC (Varughese et al 1992), 2ACT (Baker and Dodson 1980), 1MEG (Katerelos et al 1996), 2CIO (Alphey and Hunter 2006). Two other mutant structures, 2DZZ (O'Farrell and Joshua-Tor 2007) and 2E00 (O'Farrell and Joshua-Tor 2007), of bleomycin hydrolases were also included for the molecular dynamics (MD)-simulation studies only.

\subsection{Identification of conserved structural water molecules}

The conserved water molecules of plant thiol proteases in their X-ray structures (table 1) were identified by a standard least- square fitting algorithm using the Swiss PDB Viewer program (Guex et al 2001). The X-ray structure of 1PPN was taken as the template and the reference structures were superimposed on the backbone atoms of the template structure and the root mean square deviation (RMSD) values were within $\sim 0.3-0.7$ $\AA$. After superimposing the concerned individual structures on the template (1PPN), the conserved water molecule occupation sites were compared and located between the two respective structures included in table 2 . Water molecules that were found to be within $1.5 \AA$ (Mustata and Briggs 2004) in the PDB structures were taken as conserved.

\subsection{Water mobility}

The mobility of the crystal water molecules was calculated by using the respective B-factors (Mustata and Briggs 2004).

$$
\text { Mobility } \mathrm{W}_{\mathrm{i}}=\frac{\mathrm{BWi} / \mathrm{B}-\text { aver }}{\text { OWi-O-aver }}
$$

where $\mathrm{BWi}$ represents the temperature factor for the particular crystal water molecule, and B-aver denotes the average temperature factor for all the water molecules present in the respective X-ray structures. Occupancy of OWi indicates occupancy for $i$ th water molecule (usually 1) and $\mathrm{O}$-aver is the average occupancy of all water molecules present in the individual structure.

\subsection{Energy minimization of PDB structures}

All the PDB structures of plant thiol proteases (including water molecules) were taken for energy minimization.

Table 1. Surveyed crystal structures of some plant thiol proteases and bleomycin hydrolase

\begin{tabular}{lllllll}
\hline $\begin{array}{l}\text { PDB code } \\
\text { (Year deposited) }\end{array}$ & $\begin{array}{l}\text { Resolution } \\
{[\AA]}\end{array}$ & R-factor & $\begin{array}{l}\text { Mutation } \\
\text { (if any) }\end{array}$ & $\begin{array}{l}\text { No. of water } \\
\text { molecules }\end{array}$ & $\begin{array}{l}\text { Solvent other } \\
\text { than water }\end{array}$ & Reference \\
\hline 1PPN* (1991) & 1.60 & 0.16 & No & 226 & 1 & Pickersgill et al 1992 \\
9PAP (1986) & 1.65 & 0.161 & No & 195 & 29 & Kamphuis et al 1984 \\
1PE6 (1991) & 2.10 & 0.159 & No & 181 & 14 & Yamamoto et al 1991 \\
1PPP (1993) & 1.90 & 0.194 & No & 205 & 1 & Kim et al 1992 \\
1KHP (2001) & 2.00 & 0.185 & No & 53 & - & Janowski et al 2004 \\
1KHQ (2001) & 1.60 & 0.149 & No & 105 & - & Janowski et al 2004 \\
1BP4 (1998) & 2.20 & 0.190 & No & 88 & - & LaLonde et al 1998 \\
1AEC (1992) & 1.86 & 0.145 & No & 268 & - & Varughese et al 1992 \\
2ACT (1979) & 1.70 & 0.171 & No & 272 & - & Baker and Dodson 1980 \\
1MEG (1996) & 2.00 & 0.193 & D158E & 94 & - & Katerelos et al 1996 \\
2CIO (2006) & 1.50 & 0.179 & No & 161 & - & Alphey and Hunter 2006 \\
2DZZ (2006) & 2.15 & 0.190 & N392V & 258 & - & O'Farrell and Joshua-Tor 2007 \\
2E00 (2006) & 2.00 & 0.212 & N392L & 259 & - & O'Farrell and Joshua-Tor 2007 \\
\hline
\end{tabular}


Table 2. Invariant water molecules in the different X-ray crystal structures of plant thiol protease

\begin{tabular}{llllllllllll}
\hline S. no. & 1PPN & 9 PAP & 1PE6 & 1 PPP & 1KHP & 1KHQ & 1BP4 & 1AEC & 2ACT & 1MEG & 2CIO \\
\hline 1 & 215 & 4 & 238 & 273 & 302 & 312 & 415 & 3 & 3 & 247 & 24 \\
2 & 216 & 1 & 237 & 221 & 301 & 304 & 413 & 7 & 7 & 248 & 11 \\
3 & 217 & 7 & 241 & 289 & 325 & 303 & 450 & 9 & 9 & 223 & 130 \\
4 & 218 & 3 & 242 & 224 & 319 & 307 & 421 & 2 & 2 & 225 & 38 \\
5 & 220 & 8 & 240 & 222 & 303 & 302 & 411 & 14 & 14 & 224 & 131 \\
6 & 221 & 13 & 264 & 404 & 345 & 301 & 449 & 26 & 26 & 221 & 129 \\
7 & 222 & 2 & 263 & 246 & 323 & 305 & 453 & 8 & 8 & 236 & 134 \\
8 & 232 & 10 & 244 & 226 & 321 & 323 & 423 & 5 & 5 & 251 & 39 \\
9 & 237 & 5 & 251 & 363 & 336 & 317 & 414 & 17 & 17 & 258 & 108 \\
10 & 252 & 19 & 250 & 351 & 311 & 341 & 436 & 15 & 15 & 281 & 101 \\
11 & 254 & 27 & 262 & 395 & 331 & 316 & 457 & 16 & 16 & 240 & 146 \\
12 & 259 & 12 & 254 & 240 & 313 & 315 & 438 & 29 & 29 & 234 & 109 \\
13 & 279 & 16 & 228 & 223 & 346 & 308 & 451 & 6 & 6 & 220 & 132 \\
\hline
\end{tabular}

*1PPN is taken as the template structure.

*All the equivalent water molecules of the different structures were placed horizontally retaining their original PDB numbering scheme (as present in the individual PDB structure).

This was performed by a GROMOS 96 force field (Van Gunsteren and Mark 1992) (500 steps of the steepest descent followed by 1000 cycles of conjugate gradient) implemented in the Swiss PDB Viewer program with a 10 $\AA$ cut-off distance (Pisabarro et al 1994) for non-bonded interactions and a distance-dependent dielectric constant. During minimization, all residues and water molecules were allowed to move freely.

\subsection{Solvation}

All the water molecules and inhibitors present in the Xray structures were removed and all the PDB structures were then solvated by using the conditional hydrophobic accessible surface area (CHASA) program (Fleming et al 2005).

\subsection{MD simulation}

The 22 PDB- and CHASA-solvated structures were initially energy-minimized (100 cycles to eliminate initial contacts which would destabilize the integrator) using the CHARMM force field (Brooks et al 1983). After energy minimization, all the aquated structures (crystal and CHASA water molecules) were simulated using auto-interactive molecular dynamics (IMD) connected between the visualization program Visual Molecular Dynamics v. 1.8.5 (Humphrey et al 1996) and the MD program Nanoscale Molecular Dynamics v. 2.6 (Nelson et al 1996; Phillips et al 2005). The simulation was run on a workstation Xeon ${ }^{\circledR} 5160$ hardware system of
$3 \mathrm{GHz}$ and $2 \mathrm{~Gb}$ RAM. MD simulations were performed for every structure by selecting a $10 \AA$ zone around the Asn 175 residue of the catalytic triad for the IMD molten zone and fixing an $8 \AA$ zone around the IMD-molten zone for the IMD-fixed zone. The MD of all the structures were followed for $2 \mathrm{~ns}$ at $300 \mathrm{~K}$ temperature and a 2 fs time-step by means of Langevin dynamics using the CHARMM force field, which relaxed the water molecules and propagated them towards the structural equilibrium position. The fluctuations in potential energy, kinetic energy and total energy were monitored. Plots of the potential energy and kinetic energy against time at constant temperature revealed that the equilibrium was closed when the average potential energy and kinetic energy were constant, and the simulations were adequately converged within 2 ns. Different snapshots were taken at $0.5 \mathrm{~ns}$ intervals during the $2 \mathrm{~ns}$ simulation, which clearly revealed similar types of water-mediated $\mathrm{H}$ bond distances between different residues of the protein structures. Moreover, the two other mutant X-ray structures (2DZZ and 2E00) of bleomycin hydrolase were also simulated for up to $2 \mathrm{~ns}$.

\section{Results and discussion}

On detailed analysis of the X-ray structures, 13 water molecules were found to be structurally conserved in all the eleven plant thiol proteases (table 2). The two conserved water molecules W220 and W222 were seen to interact with Asn 175 of the catalytic triad in the template 1PPN structure and the equivalent conserved water molecules in the other 
structures are included in table 2. Here, W1 and W2 are assumed to be equivalent to the W220 and W222 water molecules of the 1PPN template structure and corresponding water molecules in the other structures.

The water molecules $\mathrm{W} 1$ and $\mathrm{W} 2$ form $\mathrm{H}$-bonds with the backbone oxygen $\left(\mathrm{O}_{\mathrm{b}}\right)$ atom of Asn 175. However, the W2 to $\mathrm{O}_{\mathrm{b}}$ distance was observed to be slightly more than the $\mathrm{W} 1$ to $\mathrm{O}_{\mathrm{b}}$ distance in most of the structures. The temperature factors (B-factors) and mobilities of the two water molecules (W1 and W2) are given in table 3. The comparable average Bfactors and the subsequent mobility of these two conserved water molecules in most of the structures with their $\mathrm{H}$ bonding affinities towards Asn 175 indicate the structural importance of these conserved water molecules.

The asparagine residue of the catalytic triad has been found to form two more H-bonds, one with the backbone nitrogen $\left(\mathrm{N}_{\mathrm{b}}\right)$ atom of Asn to the backbone oxygen $\left(\mathrm{O}_{\mathrm{b}}\right)$ atom of Gly 185 at an average distance of $3.2 \AA$, and the other with the side chain oxygen atom of Asn with the backbone nitrogen $\left(\mathrm{N}_{\mathrm{b}}\right)$ atom of the Ser 176 residue at an average distance of $2.90 \AA$.

In all the X-ray structures, the W1 water molecule was observed to be present within H-bonding distance from both the $\mathrm{O}_{\mathrm{b}}$ atom of the catalytic Asn 175 residue and backbone nitrogen $\left(\mathrm{N}_{\mathrm{b}}\right)$ atom from Lys 17 (Arg 17 in 1MEG) (figure 1) with an $\mathrm{O}_{\mathrm{b}}$ to $\mathrm{W} 1$ to $\mathrm{N}_{\mathrm{b}}$ angle $\sim 120^{\circ}$ (table 3 ). Interestingly, another water molecule was also observed to form an $\mathrm{H}$ bond with the $\mathrm{W} 1$ water molecule in all the PDB structures. The appearance of a water molecule at the W1 site has also been indicated and supported in the auto-solvated (CHASA) $\mathrm{X}$-ray structures and energy-minimized structures (table 4), although no other water molecule was observed to occupy the W2 water molecule position in the solvated PDB structures.

Besides the biological or structural importance of the W2 water molecule, the involvement of the W1 water molecule in the Cys 25-His 159 ion-pair stabilization through interaction with Asn 175 was also seen in all the

Table 3. H-bonding distances $(\AA)$, angles (in degree) and the different parameters of the two invariant water molecules (W220 and W222 of 1PPN and their equivalent water molecular sites [W1 and W2] in the other plant thiol protease PDB structures)

\begin{tabular}{|c|c|c|c|c|c|}
\hline \multirow[b]{2}{*}{$\begin{array}{l}\text { PDB of } \\
\text { protein }\end{array}$} & \multicolumn{2}{|l|}{ W1 } & \multirow[b]{2}{*}{$\begin{array}{l}\quad \text { W2 } \\
\text { Water molecular } \\
\text { PDB-id (distance } \\
\text { from Asn } 175 \mathrm{O}_{\mathrm{b}} \\
\text { atom) }[\mathrm{B} \text {-factor } \\
\left.\text { of W2 in } \AA^{2}\right] \\
\text { Mobility }\end{array}$} & \multirow[b]{2}{*}{$\begin{array}{l}\text { Distance } \\
\text { between the two } \\
\text { water molecules } \\
\text { W1 and W2 }\end{array}$} & \multirow[b]{2}{*}{$\begin{array}{c}\text { Angle }\left({ }^{\circ}\right) \\
\text { subtended at } \\
\text { Asn } 175 \mathrm{O}_{\mathrm{b}}{ }^{*} \\
\text { by } \mathrm{W} 1 \text { and } \mathrm{W} 2 \\
\mathrm{~W} 1-\mathrm{O}_{\mathrm{b}}-\mathrm{W} 2\end{array}$} \\
\hline & $\begin{array}{l}\text { Water molecular PDB-id (distance from } \\
\text { Asn } 175 \mathrm{O}_{\mathrm{b}}^{*} \text { atom, Lys } 17 \mathrm{~N}_{\mathrm{b}}{ }^{* *} / \text { Angle } \\
\left.\mathrm{O}_{\mathrm{b}}-\mathrm{W} 1-\mathrm{N}_{\mathrm{b}} \text { ) [B-factor of } \mathrm{W} 1 \text { in } \AA^{2}\right] \\
\text { Mobility }\end{array}$ & $\begin{array}{l}\text { H-bonding association } \\
\text { with other water } \\
\text { molecules and the } \\
\text { distances / }(\AA)\end{array}$ & & & \\
\hline $1 \mathrm{PPN}$ & W220 (2.80/2.83/117.25) [9.95] 0.2628 & W $219(2.68)$ & $\begin{array}{l}\text { W222 (3.22) } \\
{[7.26] 0.1917}\end{array}$ & 5.41 & 127.64 \\
\hline 9PAP & W8 (2.80/2.70/118.15) [10.09] 0.2466 & W28 (2.34) & $\begin{array}{l}\text { W2 (3.48) [7.19] } \\
0.1757\end{array}$ & 5.61 & 120.01 \\
\hline 1PE6 & W240 $(2.93 / 2.85 / 116.09)[10.45] 0.2709$ & W239 (2.74) & $\begin{array}{l}\text { W263 (3.63) } \\
{[5.95] 0.1542}\end{array}$ & 5.79 & 123.66 \\
\hline 1PPP & W222 (3.06/2.99/107.71) [5.20] 0.1800 & W $288(2.45)$ & $\begin{array}{l}\text { W246 (3.41) } \\
{[4.01] 0.1388}\end{array}$ & 5.83 & 128.53 \\
\hline $1 \mathrm{KHP}$ & W303 (2.67/2.83/124.13) [22.14] 0.6065 & W330 (2.56) & $\begin{array}{l}\text { W323 (3.54) } \\
{[25.39] 0.6955}\end{array}$ & 5.50 & 123.94 \\
\hline $1 \mathrm{KHQ}$ & W302 $(2.78 / 2.85 / 118.67)[16.61] 0.4668$ & W393 (2.77) & $\begin{array}{l}\text { W305 (3.38) } \\
{[15.8] 0.4440}\end{array}$ & 5.51 & 126.74 \\
\hline 1BP4 & W411 (2.87/2.79/113.89) [6.90] 0.2470 & W468 (2.62) & $\begin{array}{l}\text { W453 (3.37) } \\
{[14.43] 0.5167}\end{array}$ & 5.60 & 127.58 \\
\hline *1AEC & W14 (2.72/2.90/120.32) [5.61] 0.1621 & W $19(2.80)$ & $\begin{array}{l}\text { W8 (3.52) [5.59] } \\
0.1615\end{array}$ & 5.58 & 126.26 \\
\hline$* 2 \mathrm{ACT}$ & W14 (2.82/2.85/117.59) [10.63] 0.2949 & W $19(2.76)$ & $\begin{array}{l}\text { W8 (3.52) [9.39] } \\
0.2605\end{array}$ & 5.61 & 127.82 \\
\hline *1MEG & W224 (2.91/2.68/117.68) [5.76] 0.2784 & W $222(2.93)$ & $\begin{array}{l}\text { W236 (3.13) } \\
{[6.35] 0.3070}\end{array}$ & 5.38 & 125.77 \\
\hline $2 \mathrm{CIO}$ & W131 (2.72/2.78/115.70) [10.20] 0.2968 & W51 (2.67) & $\begin{array}{l}\text { W134 (3.28) } \\
{[9.04] 0.2631}\end{array}$ & 5.45 & 130.43 \\
\hline
\end{tabular}

*Lys 17 and Asn 182 - for 1AEC, 2ACT. **Arg 17 and Asn 179 - for $1 \mathrm{MEG}$. 


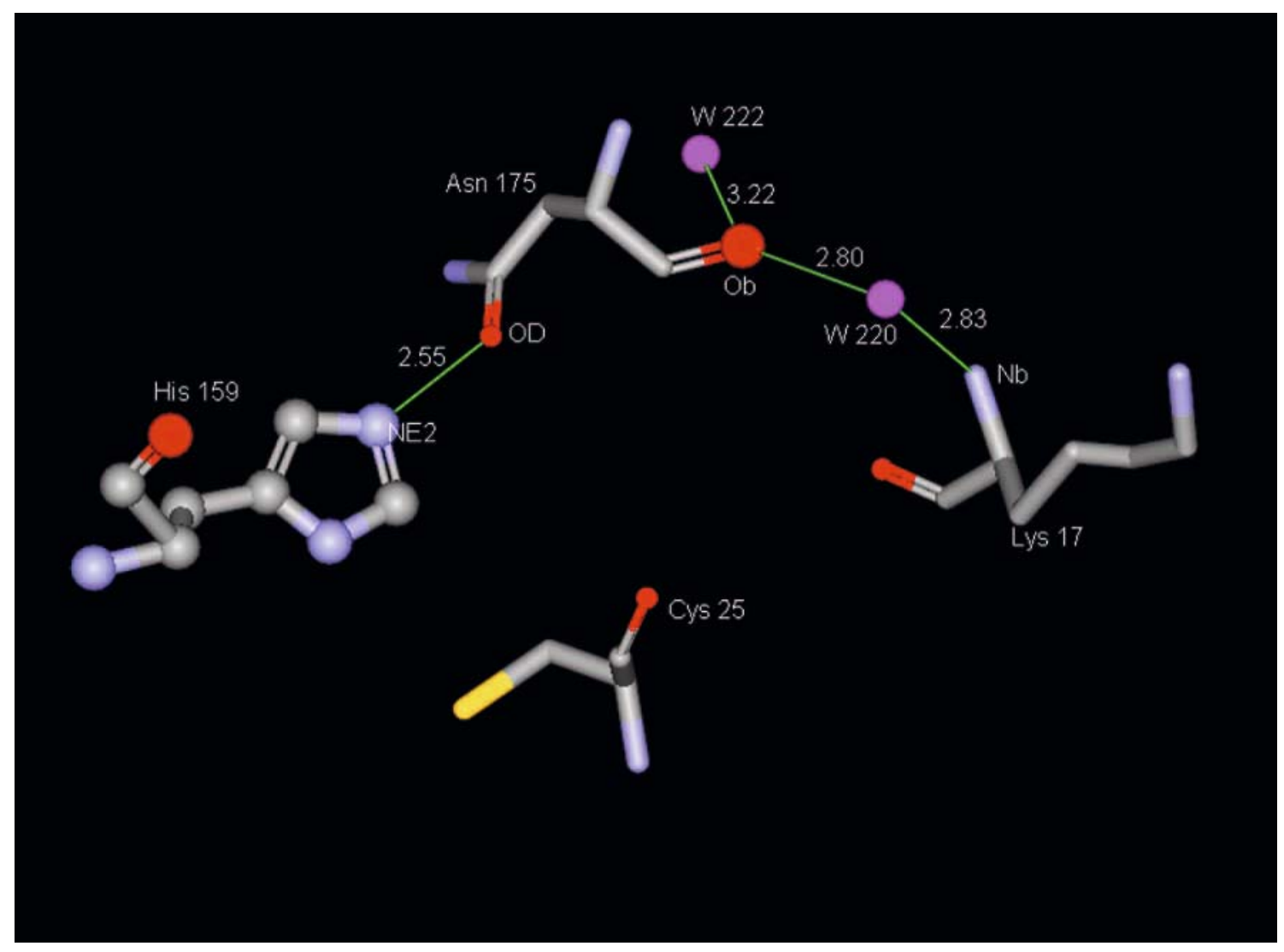

Figure 1. The H-bonding network of $\mathrm{W} 1, \mathrm{~W} 2$ and asparagine residue of the catalytic triad.

Table 4. H-bonding parameters of the invariant W1 water molecule with the Asn 175 and Lys 17 residues in the different energy minimized (E-Min), PDB and auto-solvated structures

\begin{tabular}{|c|c|c|c|}
\hline $\begin{array}{l}\text { Protein (PDB water molecule) } \\
\text { (positionally equivalent water } \\
\text { molecule in the EM PDB and } \\
\text { auto-solvated structures) }\end{array}$ & $\begin{array}{c}\text { Distance of W1 }(\AA) \text { from the } \\
\text { Asn } 175 \mathrm{O}_{\mathrm{b}} / \mathrm{Asn} 182 \mathrm{O}_{\mathrm{b}}^{*} / \mathrm{Asn} \\
179 \mathrm{O}_{\mathrm{b}} * * \text { in the EM PDB and } \\
\text { auto-solvated structures }\end{array}$ & $\begin{array}{l}\text { Distance of W1 }(\AA) \text { from the } \\
\text { Lys } 17 \mathrm{~N}_{\mathrm{b}} / \operatorname{Arg} 17 \mathrm{~N}_{\mathrm{b}}^{* *} \text { in the } \\
\text { EM PDB and auto-solvated } \\
\text { structures }\end{array}$ & $\begin{array}{c}\text { Angle } \mathrm{O}_{\mathrm{b}}-\mathrm{W} 1-\mathrm{N}_{\mathrm{b}}\left({ }^{\circ}\right) \text { in both } \\
\text { the EM PDB and auto- solvated } \\
\text { structures }\end{array}$ \\
\hline 1PPN (W220)/[W321] & $2.96 / 2.50$ & $2.90 / 2.95$ & $130.63 / 123.73$ \\
\hline 9PAP (W8)/[W314] & $3.20 / 2.51$ & $2.95 / 2.95$ & $140.01 / 119.49$ \\
\hline 1PE6 (W240)/[W316] & $3.33 / 2.93$ & $2.90 / 2.95$ & $132.14 / 113.02$ \\
\hline 1PPP (W222)/[W321] & $3.73 / 2.92$ & $6.58 / 2.95$ & $60.73 / 112.54$ \\
\hline 1KHP (W303)/[W322] & $3.59 / 2.82$ & $3.15 / 2.95$ & $128.26 / 114.86$ \\
\hline 1KHQ (W302)/[W317] & $3.24 / 2.71$ & $2.72 / 2.95$ & $120.18 / 117.15$ \\
\hline 1BP4 (W411)/[W323] & $3.40 / 2.75$ & $2.88 / 2.95$ & $116.76 / 112.57$ \\
\hline 1AEC (W 14)/[W336] & $3.44 / 2.60$ & $2.72 / 2.95$ & $129.23 / 123.09$ \\
\hline 2ACT (W 14)/[W335] & $2.73 / 2.56$ & $2.72 / 2.95$ & $127.96 / 122.92$ \\
\hline 1MEG (W224)/[W331] & $3.65 / 2.49$ & $2.83 / 2.95$ & $127.87 / 123.02$ \\
\hline 2CIO (W131)/[W320] & $3.05 / 2.48$ & $2.82 / 2.95$ & $118.81 / 117.72$ \\
\hline
\end{tabular}

*Lys 17 and Asn $182^{-}$for 1AEC, 2ACT **Arg 17 and Asn 179 - for 1MEG.

*Lys 17 and Asn 175 - for other PDB structures.

energy-minimized structures. After energy minimization, the W2 water molecule shifts from $2.80 \AA$ to an average distance of $5.95 \AA$ from the Asn $175 \mathrm{O}_{\mathrm{b}}$ atom, whereas the $\mathrm{W} 1$ water molecule almost retains its original previous 


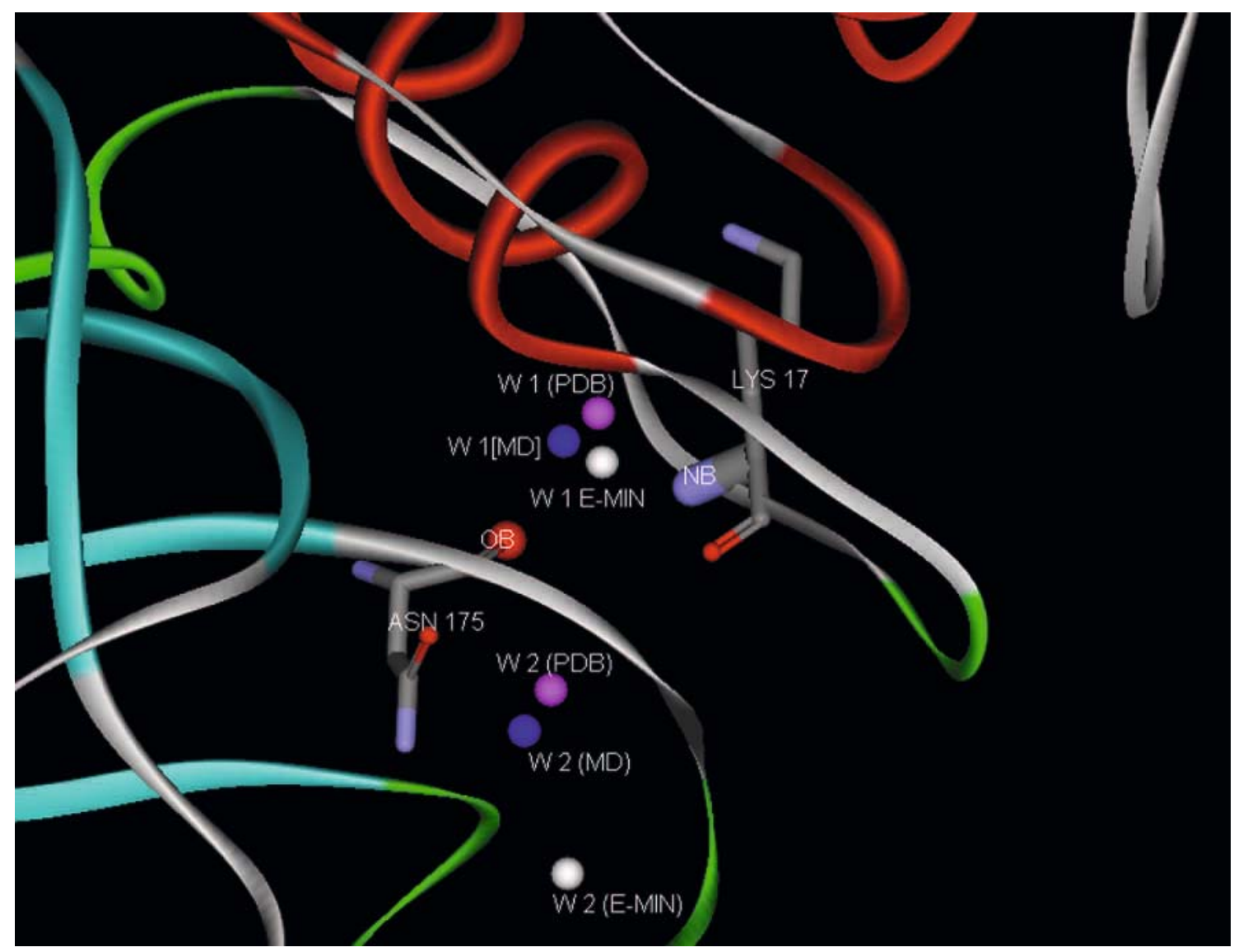

Figure 2. The relative positions of the $\mathrm{W} 1$ and $\mathrm{W} 2$ sites in PDB, E-Min (energy-minimized) and MD (molecular dynamics)-simulated structure

position. However, if the two water molecules $\mathrm{W} 1$ and W2 are removed from the structures and all the other water molecules are retained, energy minimization reveals the appearance of a new water molecule (W219 in 1PPN) at the $\mathrm{W} 1$ site near Asn 175. This W219 water molecule (which is not $\mathrm{H}$-bonded to any residue of the protein) is at a distance of $\sim 2.68 \AA$ from the $\mathrm{W} 1$ invariant site. However, no water molecules are observed within $3.5 \AA$ of the conserved molecular position of W2. Again, following energy minimization, retaining all water molecules except $\mathrm{W} 1$ reveals the appearance of another water molecule at the $\mathrm{W} 1$ invariant site, which indicates the importance of the hydrophilic W1 water molecule. Thus, the invariant position of the W1 water molecule may be indispensable in the architecture of the papain fold or protease activity.

The MD simulation studies of three CHASA-solvated PDB structures (1KHP, 2ACT and 1AEC) clearly revealed the presence of the $\mathrm{W} 1$ water molecule at a conserved hydrophilic centre. However, another water molecule was observed to occupy the position during the 2 ns simulation of the 1PE6, 1PPP, 1BP4 and 2CIO structures. During the simulation, the W1 water molecule was observed to form $\mathrm{H}$-bonds with both the $\mathrm{O}_{\mathrm{b}}$ of Asn 175 and $\mathrm{N}_{\mathrm{b}}$ atom of Lys 17 at average distances of $\sim 2.67-3.3 \AA$ and $\sim 2.97-3.23 \AA$, respectively, in the CHASA-solvated and X-ray structures (table 5) (figure 2). Some discrepancies in the $\mathrm{H}$-bond distances were observed in the 9PAP and 1MEG structures. It should be noted that the W2 water molecule site was not found to be occupied during MD simulation in all CHASAsolvated structures, implying that H-bonding of the W1 water molecular site is more pertinent when compared with the W2 conserved centre. During the simulation of up to $2 \mathrm{~ns}$, the consecutive fluctuation of $\mathrm{W} 1$ to $\mathrm{O}_{\mathrm{b}}($ Asn 175) H-bond lengths was from 2.81 to $3.45 \AA$, and $\mathrm{W} 2$ to $\mathrm{O}_{\mathrm{b}}$ (Asn 175) was 2.64 to $3.37 \AA$ (at successive $0.5 \mathrm{~ns}$ intervals). The RMSD calculation of the backbone atoms of individual conformation (relative to the minimized crystal structures) at different time intervals showed the involvement of the W1 and W2 water molecules in fixing the orientation of the Asn residue of the catalytic triad. The involvement of the two water molecules was further studied by MD simulation of the two mutant (X-ray) structures, $2 \mathrm{DZZ}$ and 2E00. On analysis of the MD simulation of $2 \mathrm{DZZ}$ 
Table 5. Molecular dynamics - simulation studies of the different plant thiol protease structures

\begin{tabular}{|c|c|c|c|}
\hline Protein & $\begin{array}{l}\text { Water present before MD at W1 position in } \\
\text { the auto-solvated PDB structures with the } \\
\text { distances }\left(\text { Asn } 175 \mathrm{O}_{\mathrm{b}} \text { atom } / \text { Lys } 17 \mathrm{~N}_{\mathrm{b}}\right) \text { in } \\
(\AA) \text { and angle }\left(\mathrm{O}_{\mathrm{b}}-\mathrm{W} 1-\mathrm{N}_{\mathrm{b}}\right) \text { in degrees }\end{array}$ & $\begin{array}{l}\text { Water present after MD at } \mathrm{W} 1 \text { position } \\
\text { in the auto-solvated PDB structures } \\
\text { with the distances (Asn } 175 \mathrm{O}_{\mathrm{b}} \text { atom/ } \\
\left.\text { Lys } 17 \mathrm{~N}_{\mathrm{b}}\right) \text { in }(\AA) \text { and angle }\left(\mathrm{O}_{\mathrm{b}}-\mathrm{W} 1-\right. \\
\left.\mathrm{N}_{\mathrm{b}}\right) \text { in degrees }\end{array}$ & $\begin{array}{l}\text { W } 1 \text { position in the MD-simulated } \\
\text { X-ray structures (distances of } \mathrm{W} 1 \text { to } \\
\text { Asn } 175 \mathrm{O}_{\mathrm{b}} / \mathrm{Lys} 17 \mathrm{~N}_{\mathrm{b}} \text { and angle } \mathrm{O}_{\mathrm{b}} \\
-\mathrm{W} 1-\mathrm{N}_{\mathrm{b}} \text { ) }\end{array}$ \\
\hline $1 \mathrm{PPN}$ & W $321(2.50 / 2.95) / 123.73$ & W $297(2.67 / 3.21) / 129.60$ & $3.45 / 2.88 / 105.12$ \\
\hline 9PAP & W $314(2.51 / 2.95) / 119.49$ & W $314(6.26 / 4.73) / 76.04$ & $2.65 / 3.21 / 119.74$ \\
\hline 1PE6 & W $316(2.93 / 2.95) / 113.02$ & W $293(2.80 / 3.23) / 154.61$ & $2.80 / 2.77 / 159.34$ \\
\hline 1PPP & W $321(2.92$ / 2.95) / 112.54 & W $299(2.82$ / 3.6) / 132.38 & $3.10 / 3.88 / 87.21$ \\
\hline $1 \mathrm{KHP}$ & W $322(2.82$ / 2.95) / 114.86 & W $322(3.14$ / 2.89) / 140.60 & $2.60 / 2.76 / 122.20$ \\
\hline $1 \mathrm{KHQ}$ & W $317(2.71 / 2.95) / 117.15$ & W $343(2.77$ / 6.9) / 61.07 & $2.94 / 3.02 / 124.57$ \\
\hline 1BP4 & W $323(2.75$ / 2.95) / 112.57 & W $296(2.64$ / 2.97) / 161.96 & $2.70 / 3.33 / 118.74$ \\
\hline 1AEC & W $336(2.60 / 2.95) / 123.09$ & W $336(3.30 / 3.09) / 126.82$ & $3.01 / 2.97 / 159.83$ \\
\hline $2 \mathrm{ACT}$ & W $335(2.56 / 2.95) / 122.92$ & W $335(2.71 / 2.97) / 126.30$ & $2.84 / 3.23 / 130.34$ \\
\hline $1 \mathrm{MEG}$ & W $331(2.49 / 2.95) / 123.02$ & W $357(3.32$ / 6.16) / 63.93 & $3.14 / 2.85 / 116.00$ \\
\hline $2 \mathrm{CIO}$ & W $320(2.48$ / 2.95) / 117.72 & W $299(2.89$ / 3.0) /121.24 & $2.65 / 2.79 / 172.84$ \\
\hline
\end{tabular}

(where Asn 392 is mutated by Valine), no water molecule was found to occupy the W1 and W2 invariant sites, and the SG atom of the catalytic Cys 73 residue shifted by around 0.9 Å. But in $2 \mathrm{E} 00$ (where Asn 392 is mutated by Leucine), the two water molecules were found to occupy the W1 and W2 invariant sites and the SG atom of the catalytic Cys 73 shifts by $0.3 \AA$ only. With the fluctuation of the H-bond distances between the water molecules and backbone oxygen atom, the side-chain orientation of the catalytic asparagine may possibly change due to the change in the H-bonding pattern of Asn during simulation. Hence, the W1 and W2 water molecules may be thought to play a role in fixing the orientation of the side chain of catalytic Asn and thus controlling the H-bond distances between its side chain amide oxygen atom and the $\mathrm{N}^{\mathrm{E} 2} \mathrm{H}$ atom of the imidazole ring of catalytic His 159.

\section{Conclusions}

These results suggest that both the water molecules (W220 and W222 of 1PPN) at the W1 and W2 invariant sites are responsible for orientating the asparagine residue of the catalytic triad, which is important for the formation of the $\mathrm{H}$-bond between its side chain amide oxygen atom and the $\mathrm{N}^{\mathrm{E} 2} \mathrm{H}$ atom of the imidazole ring of catalytic His 159. From this study, it is suggested that H-bonding of the invariant site of the W1 water molecule is more important in stabilizing the asparagine residue at the active site of the catalytic triad.

\section{Acknowledgements}

We thank NIT-Durgapur for providing TEQIP research facilities.

\section{References}

Alphey M S and Hunter W N 2006 High-resolution complex of papain with remnants of a cysteine protease inhibitor derived from Trypanosoma brucei; Acta Crystalogr. F62 504-508

Baker E N and Dodson E J 1980 Crystallographic refinement of the structure of actinidin at $1.7 \AA$ resolution by Fast Fourier LeastSquares Methods; Acta Crystalogr. A 36 559-572

Berman H M, Westbrook J, Feng Z, Gilliand G, Bhat T N, Weissig H, Shindyalov I N and Bourne P E 2000 The Protein Data Bank; Nucleic Acids Res. 28 235-242

Brooks B R, Bruccoleri R E, Olafson B D, States D J, Swaminathan S and Karplus M 1983 CHARMM: a program for macromolecular energy, minimization, and dynamics calculations; J. Comput. Chem. 4 187-217

Fleming P J, Fitzkee N C, Mezei M, Srinivasan R and Rose G D 2005 A novel method reveals that solvent water favors polyproline II over $\beta$-strand conformation in peptide and unfolded proteins: conditional hydrophobic accessible surface area (CHASA); Protein Sci. 14 111-118

Guex N, Diemand A, Peitsch M C and Schwede T 2001 The Deep View - The Swiss-PdbView program, An environment for comparative protein modeling, (Glaxo SmithKline R\&D)

Humphrey W, Dalke A and Schulten K 1996 VMD - visual molecular dynamics; J. Mol. Graph. 14 33-38

Janowski R, Kozak M, Jankowska E, Grzonka Z and Jaskolski M 2004 Two polymorphs of a covalent complex between papain and a diazomethylketone inhibitor; J. Pept. Res. 64 141-150

Kamphuis I G, Kalk K H, Swarte M B and Drenth J 1984 Structure of papain refined at $1.65 \AA$ resolution; J. Mol. Biol. 179 233-256

Katerelos N A, Taylor M A, Scott M, Goodenough P W and Pickersgill R W 1996 Crystal structure of a caricain D158E mutant in complex with E-64; FEBS Lett. 392 35-39

Kim M J, Yamamoto D, Matsumoto K, Inoue M, Ishida T, Mizuno H, Sumiya S and Kitamura K 1992 Crystal structure of papain- 
E64-c complex. Binding diversity of E64-c to papain S2 and S3 subsites; Biochem. J. 287 797-803

Komatsu K, Tsukuda K, Hosoya J and Satoh S 1986 Elevations of cathepsin B and cathepsin L activities in forelimb and hind muscles of genetically dystrophic mice; Exp. Neurol. 93 642-646

LaLonde J M, Zhao B, Smith W W, Janson C A, DesJarlais R L, Tomaszek T A, Carr T J, Thompson S K, Oh H J, Yamashita D S, Veber D F and Abdel-Meguid S S 1998 Use of papain as a model for the structure-based design of cathepsin $\mathrm{K}$ inhibitors: crystal structures of two papain-inhibitor complexes demonstrate binding to S'-subsites; J. Med. Chem. 41 4567-4576

Mustata G and Briggs J M 2004 Cluster analysis of water molecules in alanine racemase and their putative structural role; Protein Eng. Des. Sel. 17 223-234

Nelson M, Humphrey W, Gursoy A, Dalke A, Kale L, Skeel R D and Schulten K 1996 NAMD - A parallel, object-oriented molecular dynamics program; Int. J. Supercomput. Appl. High Perform. Comput. 10 251-268

O'Farrell P A and Joshua-Tor L 2007 Mutagenesis and crystallographic studies of the catalytic residues of the papain family protease bleomycin hydrolase: new insights into activesite structure; Biochem. J. 401 421-428
Pickersgill R W, Harris G W and Garman E 1992 Structure of monoclinic papain at 1.60 Angstrom resolution; Acta Crystalogr. B48 59-67

Pisabarro M T, Ortiz A R, Serrano L and Wade R C 1994 Homology modeling of the Ab1-SH 3 domain; Proteins 20 203-215

Phillips J C, Braun R, Wang W, Gumbart J, Tajkhorshid E, Villa E, Chipot C, Skeel R D, Kale L and Schulten K 2005 Scalable molecular dynamics with NAMD; J. Comput. Chem. 26 $1781-1802$

Polgár L 1974 Mercaptide-imidazolium ion-pair: the reactive nucleophile in papain catalysis; FEBS Lett. 47 15-18

Van Gunsteren W F and Mark A E 1992 On the interpretation of biochemical data by molecular dynamics computer simulation; Eur. J. Biochem. 204 947-961

Varughese K I, Su Y, Cromwell D, Hasnain S and Xuong N H 1992 Crystal structure of an actinidin-E-64 complex; Biochemistry 31 $5172-5176$

Vernet T, Tessier D C, Chatellier J, Plouffe C, Lee T S, Thomas D Y, Storer A C and Menard R 1995 Structural and functional roles of asparagine 175 in the cysteine protease papain; J. Biol. Chem. 270 16645-16652

Yamamoto D, Matsumoto K, Ohishi H, Ishida T, Inoue M, Kitamura K and Mizuno H 1991 Refined X-ray structure of papain.E-64-c complex at 2.1- Å resolution; J. Biol. Chem. 266 14771-14777

MS received 21 July 2008; accepted 12 December 2008

ePublication: 9 January 2009

Corresponding editor: DipAnKar CHATTERJI 